\title{
Analysis of phenolic profile, total phenolic content and antioxidant activity in Anacardium occidentale leaves
}

\author{
${ }^{1}$ Sassi, A., ${ }^{2}$ Normah, H., ${ }^{1}$ Khattak, M.M.A.K. and ${ }^{1, *}$ Hanapi, M.J. \\ ${ }^{1}$ Department of Nutrition Sciences, Kulliyyah of Allied Health Sciences, International Islamic University \\ Malaysia. \\ ${ }^{2}$ Department of Biotechnology, Kulliyyah of Science, International Islamic University Malaysia.
}

\begin{abstract}
Article history:
Received: 12 February 2021

Received in revised form: 30

March 2021

Accepted: 10 June 2021

Available Online: 9 January 2022
\end{abstract}

\section{Keywords:}

Anacardium occidentale,

Phenolics acids,

Flavonoids,

HPLC,

Antioxidants

DOI:

https://doi.org/10.26656/fr.2017.6(1).105

\begin{abstract}
Anacardium occidentale young leaves are consumed traditionally as part of a Southeast Asian diet. The regular consumption is believed to have beneficial effects on health in general and potentially against type 2 Diabetes mellitus due to its high content of polyphenols. This study was aimed to investigate the polyphenol content of the plant using two methanol extracts; Free Phenolic Extract (FPE) and Bound Phenolic Extract (BPE) as well as highlight the presence of six phenolic acids and flavonoids namely; gallic acid, sinapinic acid, caffeic acid, ferulic acid, quercetin and kaempferol using High performance liquid chromatography-photodiode array (HPLC-UV-Vis). The results for polyphenols and flavonoids content showed high amounts of total polyphenols in BPE with $8.5 \pm 0.57 \mathrm{mg} \mathrm{GAE} / \mathrm{g}$ as well as high amounts of total flavonoids in both extracts FPE and BPE with $0.58 \pm 0.06$ and $0.86 \pm 0.05 \mathrm{mg} \mathrm{QE} / \mathrm{g}$ respectively $(\mathrm{p}<0.05)$. The presence of these polyphenols was further confirmed by measuring the antioxidant activity through the scavenging of the free radical DPPH which showed an $\mathrm{IC}_{50}$ value for FPE $(5.17 \pm 0.64 \mu \mathrm{g} /$ $\mathrm{mL}$, BPE $(4.96 \pm 0.12 \mu \mathrm{g} / \mathrm{mL})$ compared to the positive control ascorbic acid $(4.91 \pm 0.43$ $\mu \mathrm{g} / \mathrm{mL})$. The high-performance liquid chromatography-photodiode array confirmed the presence of all four targeted phenolic acids with the highest amount showing in gallic acid and sinapinic acid in BPE with $148.12 \pm 6.44 \mu \mathrm{g}$ gallic acid/g dry weight and $47.02 \pm 1.94$ $\mu \mathrm{g}$ sinapinic acid/g dry weight respectively. As for flavonoids, quercetin was present in both extracts with $20.38 \pm 1.22 \mu \mathrm{g} / \mathrm{g}$ dry weight in BPE and $5.21 \pm 0.1 \mu \mathrm{g} / \mathrm{g}$ dry weight in FPE while Kaempferol was not detectable in either extract. These findings confirmed the importance of $A$. occidentale as a rich source of polyphenols which can be further investigated to determine its effects in-vitro and in-vivo on non-communicable diseases such as type 2 diabetes.
\end{abstract}

\section{Introduction}

In Southeast Asian countries, particularly Malaysia, some herbs and tree leaves are consumed raw (known as ulam) or sometimes blanched to reduce their stringent taste and are considered as appetizers in the traditional diet. It was believed that these herbs may possess healthpromoting properties such as treating dysentery, diarrhoea and piles as well as a relief for toothache and sore gums when leaves are used in an infusion (Chan et al., 2017). One of these proclaimed herbs are the leaves of Anacardium occidentale L. (A. occidentale) of the family Anacardiaceae which is native to Brazil, Portugal, India, Southeast Asia and Africa. Its English name derives from the Portuguese name for the fruit of the cashew tree which is caju. Leaves are leathery and obovate with a rounded apex, lustrous and reddish when young, and dark green when mature with prominent yellow veins (Omojate, 2014). Studies on the antiinflammatory (Souza et al., 2017), antioxidant and antimicrobial (Onuh et al., 2017) as well as the antidiabetic properties (Patel et al., 2012; Jaiswal et al., 2016) and phytochemicals derivatives from $A$. occidentale have been investigated using different parts of the plant (bark, fruit, leaves) as well as different extraction methods. The major constituents of the plant which are present in high amounts are phenolic acids which are a subclass of a larger category of metabolites known as "phenolics". This term encompasses around 8000 naturally occurring compounds, all of which possess one common structural feature, a phenol (an aromatic ring bearing at least one hydroxyl substituent). 
Phenolics are divided into polyphenols and simple phenols based solely on the number of phenol subunits present; polyphenols possessing at least two phenol subunits include the flavonoids, and those compounds possessing three or more phenol subunits are referred to as the tannins (Neveu et al., 2010). Phenolic acids in plants may exist in free, soluble conjugated (esterified), and insoluble-bound forms. Studies have illustrated that phenolic acid conjugates are recognized antioxidants with anti-inflammatory properties both in vitro and in vivo (dos Santos et al., 2006). They have also been associated with diverse functions, including nutrient uptake, protein synthesis, enzyme activity, photosynthesis, structural components and allelopathy (Yang et al., 2018). These two forms of phenolic acids, considered to be bound to oligosaccharides, peptides or polysaccharides, can be released after acidic or alkaline hydrolysis. Therefore, there should be a comprehensive analysis of all forms of free, conjugated, and bound phenolics (Gao et al., 2017). The most commonly occurring phenolic acids are Gallic acid which is mostly found in tea, Caffeic acid (both free and esterified) which represents around $75 \%$ of the total hydroxycinnamic acid content of most fruits followed by Ferulic acid which is the most abundant phenolic acid found in cereal grains (Manach, 2004). The second type of polyphenols are flavonoids which represent a large family of compounds (over 4,000 flavonoids have been identified) synthesized by plants that are categorized, according to chemical structure, into flavonols, flavones, flavanones, isoflavones, anthocyanidins and flavanols (catechins and proanthocyanidins) (Manach, 2004). The most commonly known flavonoids are Quercetin and Kaempferol. The phenolic profile of $A$. occidentale has been previously investigated but mostly focused on the fruit or the bark. Since the young leaves of $A$. occidentale are widely consumed by Malaysians as part of their daily diets, the present study aimed to investigate the phenolic contents, phenolic profile and antioxidant activity of this plant to highlight its importance as a candidate for further investigation for the prevention and treatment of non-communicable diseases such as obesity and diabetes.

\section{Materials and methods}

\subsection{Chemicals}

Phenolic acid and flavonoid standards were purchased from and Sigma (St. Louis, MO, USA). Organic solvents and antioxidant chemicals were acquired from Merck (Darmstadt, Germany). Organic solvents and standards used for extraction and identification were of the highest analytical grade.

\subsection{Acquisition of plant material}

Fresh $A$. occidentale leaves were purchased from a local market in Kuantan, Pahang, Malaysia. These leaves were separated into mature leaves (dark green) and young leaves (light green and brown). For the purpose of this study, the young leaves were used as they contain higher amounts of polyphenols (Chan et al., 2017). The leaves were washed thoroughly then introduced into a freeze-drying process for 72 hours then five grams were weighed and homogenized accordingly for a better sample disruption before proceeding further to the extraction.

\subsection{Extraction of free and bound phenolic extracts}

The free and bound phenolics in A. occidentale were extracted using methanol according to the procedure described by Atsuko et al. (2010). Five grams of powdered $A$. occidentale were extracted two times on a shaker with $50 \mathrm{~mL}$ of absolute methanol for $1 \mathrm{~h}$. The slurry extract was then filtered through a Whatman filter paper No. 1. The extracts were pooled and desolventised using rotary evaporator (Buchi R-215, Schwabach, Germany) until a semisolid residue was obtained which was then labelled as free phenolic extract (FPE). The pellet obtained after the extraction of FPE was hydrolyzed with $50 \mathrm{~mL}$ of $4 \mathrm{M} \mathrm{NaOH}$ for $1 \mathrm{hr}$ at room temperature. The sample was acidified to $\mathrm{pH} 2$ with $6 \mathrm{~N}$ $\mathrm{HCl}$ follow by centrifugation $(4000 \times g, 10$ mins). The liberated phenolic acids were then extracted with hexane at a hexane to water ratio of $1: 1(\mathrm{v} / \mathrm{v})$ to remove free fatty acids and other lipid contaminants. The aqueous layer was then extracted 6 times with diethyl ether-ethyl acetate $(1: 1, \mathrm{v} / \mathrm{v})$. The ether-ethyl acetate extracts was filtered and evaporated to dryness under vacuum. The dried residue was dissolved in methanol and labelled as bound phenolic extract (BPE). Both FPE and BPE were kept in the freezer $\left(-20^{\circ} \mathrm{C}\right)$ until further analysis.

\subsection{Total phenolic content (TPC)}

The total phenolic content (TPC) was measured according to the method used by Agbor et al. (2014). Approximately $100 \mu \mathrm{L}$ of previously prepared Gallic acid standard dilution was mixed with $500 \mu \mathrm{L}$ of water followed by $100 \mu \mathrm{L}$ of Folin -Ciocalteu reagent (FCR) then was allowed to stand for 6 mins. $500 \mu \mathrm{L}$ of distilled water along with $1 \mathrm{~mL}$ of $7 \%$ sodium carbonate were added to the reaction mixture which was left for 90 mins in the dark and the absorbance was measured with a spectrophotometer at an absorbance of $760 \mathrm{~nm}$. The same procedure was repeated for each extract and the total phenol contents of the extracts were calculated as Gallic acid equivalents (mg GAE/g) by plotting a gallic acid standard curve. Each 
analysis was performed in triplicate.

\subsection{Total flavonoid content}

The total flavonoid content was measured according to the method used by Panche et al. (2016). Quercetin standard dilutions were mixed with $500 \mu \mathrm{L}$ of distilled water and $100 \mu \mathrm{L}$ of $5 \%$ Sodium nitrate then allowed to stand for 6 mins. $150 \mu \mathrm{L}$ of $10 \%$ Aluminium chloride solution was added to the mixture then left to stand for another 5 mins. After that, $200 \mu \mathrm{L}$ of Sodium hydroxide solution (1M) was added and the absorbance was recorded at $510 \mathrm{~nm}$ using a UV spectrophotometer. Flavonoids' content was determined as Quercetin equivalent $(\mathrm{mg} \mathrm{QE} / \mathrm{g}$ ) by plotting a quercetin standard curve. Analysis was performed in triplicate.

\subsection{Free radical scavenging activity (DPPH)}

The free radical scavenging activity was measured according to the method previously described by Kedare et al. (2011). The absorbance of a fresh solution of DPPH $(0.002 \%)$ was measured at $515 \mathrm{~nm}$. A volume of $50 \mu \mathrm{L}$ of extracts was mixed with $3 \mathrm{~mL}$ of DPPH solution and was allowed to stand in the dark for 15 mins then the absorbance was recorded once again at $515 \mathrm{~nm}$. Similarly, Ascorbic acid was used as a positive control by measuring the values of five selected concentrations $(20-100 \mu \mathrm{g} / \mathrm{mL}) . \mathrm{IC}_{50}$ values were calculated using the equation drawn from the \%inhibition vs concentration plot.

The percent inhibition of DPPH by extracts was calculated using the following equation:

$$
\% \text { Inhibition }=\frac{A-B}{A} \times 100
$$

Where $\mathrm{A}=$ absorbance of pure $\mathrm{DPPH}$ and $\mathrm{B}=$ absorbance of sample

\subsection{High performance liquid chromatography- photodiode array (HPLC-UV-Vis) analysis}

HPLC method was adopted from (Wang et al., 2004). High performance liquid chromatographyphotodiode array (HPLC-UV-VIS) analysis consisted of a Perkin Elmer HPLC coupled with UV-Vis. Analysis of bioactive compounds was performed for phenolic acid and flavonoids. Before injection, each extracted sample was filtered using a $0.45 \mu \mathrm{m}$ PTFE filter (Millipore). The C6-phenyl column $(250 \times 4.6 \mathrm{~mm}$ i.d., particle size $3 \mu \mathrm{m}$, C6-phenyl $3 \mu$; phenomenex, Torrance, CA, USA) was used at $25^{\circ} \mathrm{C}$ with the injection volume of $20 \mu \mathrm{L}$. For phenolic acid analysis, mobile phase consisted of solvent A $(2.5 \%, v / v$, solution of acetic acid in water) and solvent $\mathrm{B}(2.5 \%, \mathrm{v} / \mathrm{v}$, solution of acetic acid in methanol) at different ratios, the gradient profile was $100 \% \mathrm{~A}$ at 0 5 mins, $90 \% \mathrm{~A}$ at $15 \mathrm{mins}, 50 \% \mathrm{~A}$ at $45 \mathrm{mins}$ and $100 \%$
$\mathrm{A}$ at 55 mins. For flavonoids analysis, the mobile phase consisted of solvent A (a $1.0 \%, \mathrm{v} / \mathrm{v}$, solution of formic acid in methanol) and solvent $\mathrm{B}(\mathrm{a} 1.0 \%, \mathrm{v} / \mathrm{v}$, solution of formic acid in a methanol: water mixture, 30:70, v/v). Formic acid was added to increase peak resolution in each case. The gradient profile was $5 \% \mathrm{~A}$ at $0 \mathrm{~min}, 25 \%$ $\mathrm{A}$ at $10-15 \mathrm{~min}, 90 \% \mathrm{~A}$ at $40 \mathrm{~min}$ and $5 \% \mathrm{~A}$ at $50 \mathrm{~min}$. Flow rate was set at $1.0 \mathrm{~mL} / \mathrm{min}$ for both compounds. The PDA was set at $270 \mathrm{~nm}$ to monitor the UV/Vis absorption, UV/Vis spectra was recorded from $190 \mathrm{~nm}$ to $650 \mathrm{~nm}$. Each compound was quantified by comparing its peak area against the standard calibration curve obtained specifically for the standard solutions containing that compound. To obtain the standard calibration curves, six different standards with different concentrations were injected. The polyphenols standards used were: phenolic acids (gallic acid, sinapinic acid, caffeic acid, ferulic acid) and flavonoids (quercetin and kaempferol) (Sigma-Aldrich).

\section{Results and discussion}

Free radicals are the dominant contributor to oxidative stress which, in his turn, is thought to be a major link to all inflammatory diseases such as diabetes (Manach, 2004). Phytochemicals possess a variety of active mechanisms depending on their class. Polyphenols are the most common since they are present in almost all plants (Sulaiman, 2011). Flavonoids represent the largest sub-group in polyphenols and are mainly implicated in slowing the pathogenesis of chronic diseases through antioxidant and anti-inflammatory activities which has been linked to the prevention of certain cancers and cardiovascular diseases (Panche, 2016). In this study, we investigated the total phenolic content from the methanol extract of $A$. occidentale leaves (free and bound) using the Folin-ciocalteu method previously described by Agbor et al. (2014). Folin-Ciocalteu is a yellow acid comprised of a mixture of phosphomolybdate (H3PW12O40) and phosphotungstate (H3PMo12O40) acids. This reagent is reduced into a mixture of tungstates and molybdates characterized by their blue colour during the oxidation of phenols. The intensity of the colour is proportional to the amount of polyphenols available in the solution (Louaileche et al., 2015). The total phenolic content in the free phenolic extract (FPE) showed a value of $3.45 \pm 0.37 \mathrm{mg} \mathrm{GAE} / \mathrm{g}$ while it showed significantly higher $(p<0.05)$ amounts in the bound phenolic extract (BPE) with $8.32 \pm 0.57 \mathrm{mg} \mathrm{GAE} / \mathrm{g}$ as shown in Figure 1. This total of $12.28 \pm 2.97 \mathrm{mg} \mathrm{GAE} / \mathrm{g}$ was slightly higher compared to the amount found in a study by Andarwulan et al. (2012) using the same extraction method which was $8.47 \pm 15.05 \mathrm{mg} \mathrm{GAE} / \mathrm{g}$ and characterized $A$. occidentale as the highest yielding plant in terms of polyphenols in Southeast Asia compared to 
Total phenolics content

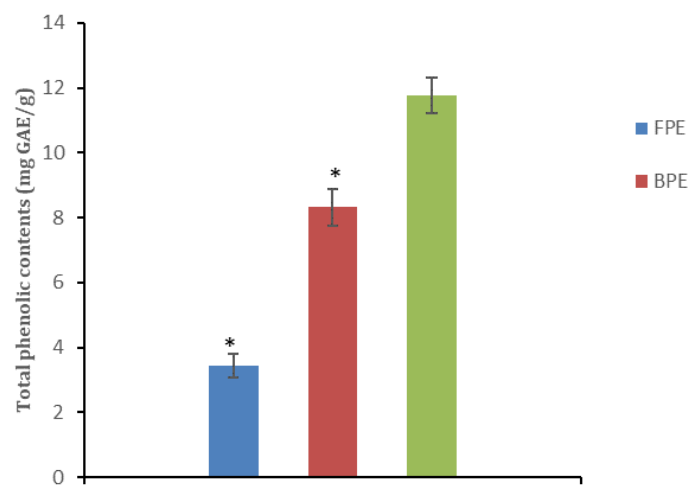

Figure 1. Total phenolic content of free and bound phenolic extracts $(\mathrm{n}=3, *=\mathrm{p}<0.05)$.

*TPC is significantly higher in BPE than FPE

other underutilized plants. A study by Madjitoloum et al. (2018), using methanol as a solvent, found the total phenolic content to be half the amount we found with a value of $6.04 \pm 0.02 \mathrm{mg} \mathrm{GAE} / \mathrm{g}$. This can be due to the different cultivars of the plant (Asian vs African varieties) which can yield a different phenolic content. Another study by Onuh et al. (2017) recorded the total polyphenols content in $A$. occidentale leaves using a different solvent (ethanolic extract) to be $10.92 \pm 3.06 \mathrm{mg} /$ g. According to Wang and Weller (2006), different extraction methods can yield different active ingredients and hence, different antioxidant activity. The most common phenolic acids present in $A$. occidentale that contribute to the aforementioned values were previously identified to be chlorogenic acid, coumaric acid, gallic acid, caffeic acid and ferulic acid (Salehi et al., 2019). The presence of the latter three phenolic acids was confirmed in our HPLC analysis in addition to sinapinic acid with values of $148.12 \pm 6.44 \mu \mathrm{g}$ gallic acid/g dry weight, $47.02 \pm 1.94 \mu \mathrm{g}$ sinapinic acid/g dry weight, $1.42 \pm 0.24 \mu \mathrm{g}$ caffeic acid/g dry weight and $5.72 \pm 0.49 \mu \mathrm{g}$ ferulic acid/g dry weight for the BPE, while the BPE only contained gallic acid and caffeic acid with values of $113.84 \pm 1.2 \mu \mathrm{g}$ gallic acid/g dry weight and $1.48 \pm 0.51 \mu \mathrm{g}$ caffeic acid/g dry weight respectively (Figure 5 and Figure 6). Anacardium occidentale leaves showed a promising amount of phenolic acids which according to Kumar and Goel (2019), even though phenolic compounds are known as direct antioxidants, they also show indirect antioxidant activity by inducing endogenous protective enzymes and positive regulatory effects on signalling pathways which depend on the state they're found in inside the plant (free, esterified or bound). The total flavonoid content of the leaves of $A$. occidentale was measured using a previously described method by Panche et al. (2016). This method is based on the formation of a complex between the aluminium ion [Al (III)] and the carbonyl and hydroxyl groups of flavones and flavonols that produce a yellow colour, the higher the intensity of the colour the higher the flavonoid content (Popova et al., 2004). In this study, the total flavonoid content of the free phenolic extract (FPE) was $0.58 \pm 0.06 \mathrm{mg}$ QE/g while it showed significantly $(\mathrm{p}<0.05)$ higher amounts in the bound phenolic extract (BPE) with $0.86 \pm 0.05 \mathrm{mg}$ QE/g as shown in Figure 2. A study by Madjitoloum et al. (2018) found lesser amounts of total flavonoids in the extracts of $A$. occidentale whole leaves with a value of $0.76 \pm 0.03 \mathrm{mg} \mathrm{QE} / \mathrm{g}$ using methanol extraction as well. This difference can be due to the difference in cultivars used in both studies. The same previously mentioned study by Andarwulan et al. (2012) also found $A$. occidentale to contain similar amounts of flavonoids in which quercetin and kaempferol were the highest yielding flavonoids. The HPLC analysis used in our study (Figure 5,6) confirmed the presence of only one flavonoid (Quercetin) with a value of $20.38 \pm 1.22 \mu \mathrm{g} / \mathrm{g}$ dry weight in BPE while showing lower values in FPE with $5.21 \pm 0.1 \mu \mathrm{g} / \mathrm{g}$ dry weight. A study by Shukri and Alan (2010) also confirmed that $A$. occidentale leaves contain high amounts of flavonoids notably quercetin, kaempferol and myricetin. This was further confirmed in a similar study by Chan et al. (2017) who identified several different flavonols which are believed to play a role in the antioxidant activity of $A$. occidentale among which quercetin was the most notable. According to Panche et al. (2016), flavonoids (mainly flavones and catechins) have been reported to be one of the most powerful antioxidants, therefore, plants containing higher amounts of flavonoids and flavonols such as quercetin have higher antioxidant potential.

DPPH (1, 1-diphenyl-2-picrylhydrazyl) is one of the most stable free radicals and the most widely used to evaluate radical scavengers in plants and foods. Antioxidants react with the unstable free radical DPPH and convert it to 1,1-diphenyl-2-picryl hydrazine which is visible via a change in colour (Alam et al., 2013). The antioxidant activity of the extracts was expressed both in $\mathrm{IC}_{50}$ (inhibitory concentration); which is defined as the efficient concentration of a substance that causes $50 \%$ loss of the activity of the radical DPPH, as well as in percentage inhibition (\%inhibition). The lower the value of $\mathrm{IC}_{50}$ the more potent the extract is as an antioxidant. On the other hand, the percentage inhibition of DPPH decreases with increasing plant concentration since the DPPH acts as a radical capture (antioxidant). As the plant extract concentration increases, the DPPH is consumed more hence, the DPPH concentration decreases (Olugbami et al., 2014). In this study, the highest scavenging activity was shown in BPE (67.2\%) and similarly in FPE (50.32\%) compared to the control ascorbic acid (63.41\%) as indicated in Figure 3. The $\mathrm{IC}_{50}$ values were respectively $1.4 \mu \mathrm{g} / \mathrm{mL}, 0.8 \mu \mathrm{g} / \mathrm{mL}$ and 1.11 


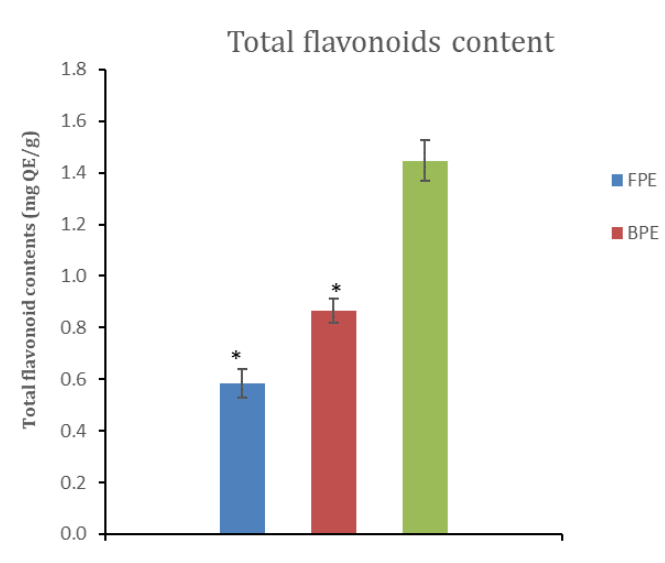

Figure 2. Total flavonoid content of free and bound phenolic extracts $(\mathrm{n}=3, *=\mathrm{p}<0.05)$

*TFC is significantly higher in BPE than FPE

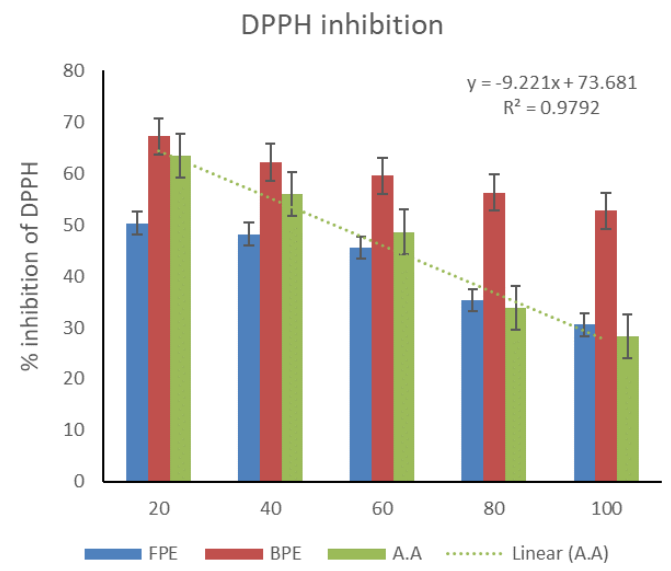

Figure 3. Percentage inhibition of DPPH between FPE (free phenolic extract), BPE (bound phenolic extract) and A.A as a positive control (ascorbic acid)

\section{$\mathrm{IC}_{50}(\mu \mathrm{G} / \mathrm{mL})$}

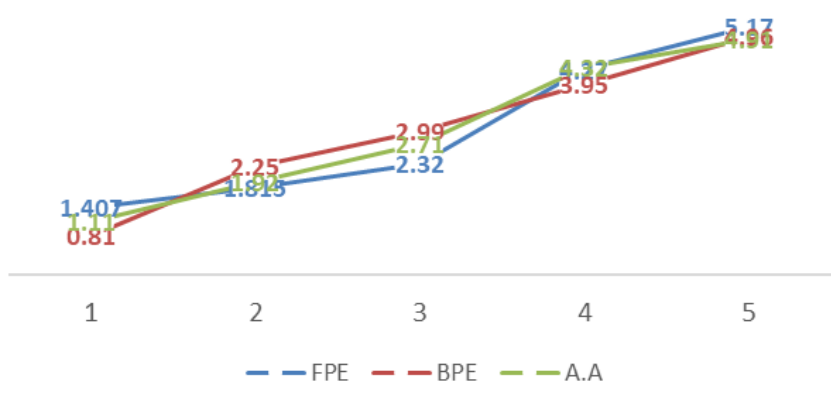

Figure $4 . \mathrm{IC}_{50}$ values of free phenolic extract bound phenolic extract and ascorbic acid $(\mu \mathrm{g} / \mathrm{mL})$

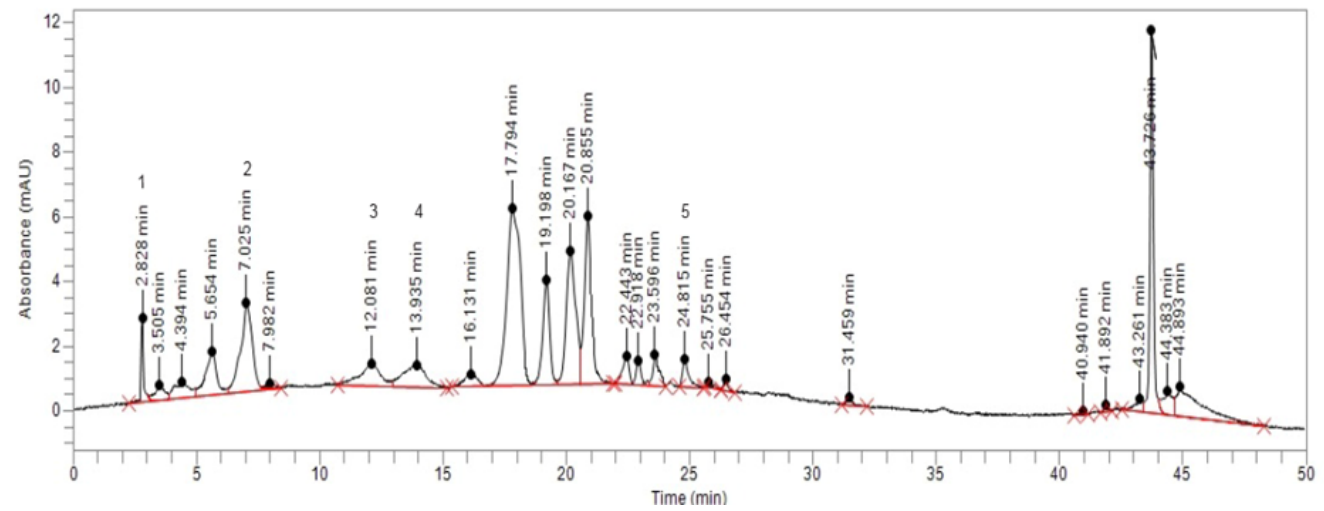

Figure 5. Chromatogram of bound phenolic extract (BPE). Peak identification: (1) Gallic acid; (2) Caffeic acid; (3) Ferulic acid; (4) Sinapinic acid; (5) Quercetin.

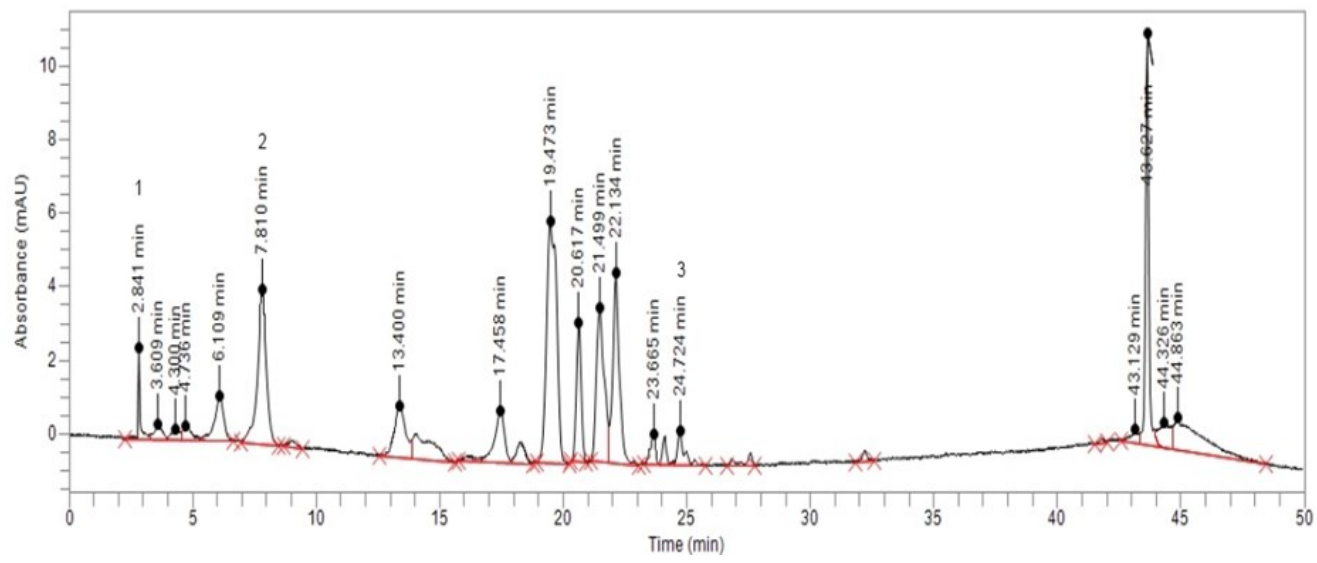

Figure 6. Chromatogram of free phenolic extract (FPE). Peak identification: (1) Gallic acid; (2) Caffeic acid; (3) Quercetin. 
$\mu \mathrm{g} / \mathrm{mL}$ for a concentration of $10 \mu \mathrm{g} / \mathrm{mL}$ of plant extract as shown in Figure 4. Given that both extracts had high phenolic acids and flavonoid content as previously mentioned, it is expected for the plant to possess high DPPH scavenging activity. A study by Ajileye et al. (2015) examining the DPPH scavenging activity on different extracts of $A$. occidentale leaves found much higher results $\left(\mathrm{IC}_{50}=5.66 \pm 0.16 \mu \mathrm{g} / \mathrm{mL}\right.$ for whole leaves extract) and showed even higher antioxidant potential using different solvents. A study by Sulaiman et al. (2011) found that the methanol extract of $A$. occidentale showed high antioxidant properties when compared to other solvents with a value of $16.2 \pm 1.2 \mathrm{mg} \mathrm{GAE} / \mathrm{g}$. The findings of this study have revealed the potential of $A$. occidentale leaf extracts as antioxidants which should be further explored and investigated.

\section{Conclusion}

Polyphenols were successfully extracted from $A$. occidentale and separated into free phenolic extract (FPE) and bound phenolic extract (BPE). Antioxidant protocols were evaluated and showed significant amounts of total polyphenols as well as flavonoids and, consequently, antioxidant activity measured using DPPH scavenging activity. Furthermore, the profiling method using HPLC revealed the presence of the targeted phenolic acids: (gallic acid, sinapinic acid, caffeic acid, ferulic acid) and flavonoids (quercetin). The results of this study highlight the importance of $A$. occidentale as a polyphenol-rich plant which requires further investigations to confirm the antioxidant effect of its extracts on in-vitro and in-vivo models.

\section{Acknowledgement}

This research was funded by the Ministry of Higher Education's Fundamental Research Grant Scheme (FRGS19-022-0630) to which the authors would like to express their gratitude as well as the International Islamic University Malaysia.

\section{References}

Agbor, G.A., Vinson, J.A. and Donnelly, P.E. (2014), Folin-Ciocalteau Reagent for Polyphenolic Assay. International Journal of Food Science and Nutrition Diet, 3(8), 147-156. https://doi.org/10.19070/23263350-1400028

Ajileye, O.O., Obuotor, E.M., Akinkunmi, E.O. and Aderogba, M.A. (2015). Isolation and characterization of antioxidant and antimicrobial compounds from Anacardium occidentale $L$. (Anacardiaceae) leaf extract. Journal of King Saud University - Science, 27(3), 244-252. https:// doi.org/10.1016/j.jksus.2014.12.004

Alam, M.N., Bristi, N.J. and Rafiquzzaman, M. (2013).

Review on in vivo and in vitro methods evaluation of antioxidant activity. Saudi Pharmaceutical Journal, 21(2), 143-152. https://doi.org/10.1016/ j.jsps.2012.05.002

Andarwulan, N., Kurniasih, D., Apriady, R.A., Rahmat, H., Roto, A.V. and Bolling, B.W. (2012). Polyphenols, carotenoids, and ascorbic acid in underutilized medicinal vegetables. Journal of Functional Foods, 4(1), 339-347. https:// doi.org/10.1016/j.jff.2012.01.003

Atsuko, Y., Keisuke, S., Yoichi, N., Takashi, N., Maki, S., Tomoyuki, O., Shunjiro, H. and Hideaki, O. (2010). Determination of Free and Bound Phenolic Acids, and Evaluation of Antioxidant Activities and Total Polyphenolic Contents in Selected Pearled Barley. Food Science and Technology Research, 16 (3), 215-224. https://doi.org/10.3136/fstr.16.215

Chan, E.W.C., Baba, S., Chan, H.T., Kainuma, M., Inoue, T. and Wong, S.K. (2017). Ulam herbs: A review on the medicinal properties of Anacardium occidentale and Barringtonia racemosa. Journal of Applied Pharmaceutical Science, 7(2), 241-247. https://doi.org/10.7324/JAPS.2017.70235

dos Santos, M.D., Almeida, M.C., Lopes, N.P. and de Souza, G.E.P. (2006). Evaluation of the antiinflammatory, analgesic and antipyretic activities of the natural polyphenol chlorogenic acid. Biological and Pharmaceutical Bulletin, 29(11), 2236-2240. https://doi.org/10.1248/bpb.29.2236

Gao, Y., Ma, S., Wang, M. and Feng, X.-Y. (2017). Characterization of Free, Conjugated, and Bound Phenolic Acids in Seven Commonly Consumed Vegetables. Molecules, 22(11), 1878. https:// doi.org/10.3390/molecules22111878

Jaiswal, Y.S., Tatke, P.A., Gabhe, S.Y. and Vaidya, A.B. (2016). Journal of Traditional and Complementary Medicine Antidiabetic activity of extracts of Anacardium occidentale Linn. leaves on nstreptozotocin diabetic rats. Journal of Traditional Chinese Medical Sciences, 7(4), 421-427. https:// doi.org/10.1016/j.jtcme.2016.11.007

Kumar, N. and Goel, N. (2019). Phenolic acids: Natural versatile molecules with promising therapeutic applications. Biotechnology Reports, 24, e00370. https://doi.org/10.1016/j.btre.2019.e00370

Manach, C. (2004). Polyphenols: food sources and bioavailability. American Journal of Clinical Nutrition, 79(5), 727-747. https://doi.org/10.1093/ ajcn/79.5.727

Neveu, V., Perez-Jiménez, J., Vos, F., Crespy, V., du 
Chaffaut, L., Mennen, L., Knox, C., Eisner, R., Cruz, J., Wishart, D. and Scalbert, A. (2010). PhenolExplorer: an online comprehensive database on polyphenol contents in foods. Database: The Journal of Biological Databases and Curation, 2010, bap024. https://doi.org/10.1093/database/bap024

Olugbami, J.O., Gbadegesin, M.A. and Odunola, O.A. (2014). In vitro evaluation of the antioxidant potential, phenolic and flavonoid contents of the stem bark ethanol extract of Anogeissus leiocarpus. African Journal of Medicine and Medical Sciences, 43(Suppl. 1), 101-109. https:// pubmed.ncbi.nlm.nih.gov/26681826

Omojate C.G., Felix O.E. and Clement O.A. (2014). A Review on the Phytochemical and AntiHyperglycaemic Properties of the Fractionated Anacardium Occidentale L Leaves, Seeds and Stem Barks Extracts. IOSR Journal of Pharmacy (IOSRPHR), 4(2), 27-32. https:// doi.org/10.9790/3013-040201027-32

Onuh, J.O., Idoko, G., Yusufu, P. and Onuh, F. (2017). Comparative Studies of the Phytochemical, Antioxidant and Antimicrobial Properties of Cashew Leaf, Bark and Fruits Extracts. American Journal of Food and Nutrition, 5(4), 115-120. https:// doi.org/10.12691/ajfn-5-4-1

Panche, A.N., Diwan, A.D. and Chandra, S.R. (2016). Flavonoids: an overview. Journal of Nutritional Science, 5, e47-e47. https://doi.org/10.1017/ jns. 2016.41

Patel, D.K., Prasad, S.K., Kumar, R. and Hemalatha, S. (2012). An overview on antidiabetic medicinal plants having insulin mimetic property. Asian Pacific Journal of Tropical Biomedicine, 2(4), 320-330. https://doi.org/10.1016/S2221-1691(12)60032-X

Shukri, M.A.M. and Alan, C. (2010). Analysis of phenolics in Anacardium occidentale shoot extracts using a reversed-phase high performance liquid chromatography tandem mass spectrometry (RPHPLC-MS). Journal of Tropical Agriculture and Food Science, 38(2), 221-230.

Souza, N.C., Oliveira, J.M. De, Morrone, S., Albanus, R.D.O., Medeiros, S., Camillo, S., Maria, S., Langassner, Z., Gelain, D.P., Cláudio, J., Moreira, F., Juliani, R., Dalmolin, S., Augusto, M. and Pasquali, D.B. (2017). Antioxidant and AntiInflammatory Properties of Anacardium occidentale Leaf Extract. Evidence-Based Complementary and Alternative Medicine, 2017(7-8), 1-8. https:// doi.org/10.1155/2017/2787308

Sulaiman, S.F., Sajak, A.A.B., Ooi, K.L., Supriatno and Seow, E.M. (2011). Effect of solvents in extracting polyphenols and antioxidants of selected raw vegetables. Journal of Food Composition and Analysis, 24(4-5), 506-515. https://doi.org/10.1016/ j.jfca.2011.01.020

Wang, H., Provan, G.J. and Helliwell, K. (2004). Determination of rosmarinic acid and caffeic acid in aromatic herbs by HPLC. Food Chemistry, 87(87), 307-311.

j.foodchem.2003.12.029

Yang, L., Wen, K.-S., Ruan, X., Zhao, Y.-X., Wei, F. and Wang, Q. (2018). Response of Plant Secondary Metabolites to Environmental Factors. Molecules, 23 (4), 762. https://doi.org/10.3390/molecules23040762 